\title{
Definition and global epidemiology of pediatric acute respiratory distress syndrome
}

\author{
Fernando Beltramo, Robinder G. Khemani \\ Children's Hospital Los Angeles, University of Southern California Keck School of Medicine, Los Angeles, CA, USA \\ Contributions: (I) Conception and design: All authors; (II) Administrative support: All authors; (III) Provision of study materials or patients: All \\ authors; (IV) Collection and assembly of data: All authors; (V) Data analysis and interpretation: All authors; (VI) Manuscript writing: All authors; (VII) \\ Final approval of manuscript: All authors. \\ Correspondence to: Fernando Beltramo, MD; Robinder G. Khemani, MD, MsCI. Children's Hospital Los Angeles, University of Southern California \\ Keck School of Medicine, 4650 Sunset Blvd, MS \#12, Los Angeles, CA 90027, USA. Email: fbeltramo@chla.usc.edu; RKhemani@chla.usc.edu.
}

\begin{abstract}
Acute respiratory distress syndrome (ARDS) has been known to occur in children since early descriptions of the disease, but pediatric specific diagnostic criteria were first established in 2015 with the Pediatric Acute Lung Injury Consensus Conference (PALICC) definition of pediatric ARDS (PARDS). There were substantial changes proposed with the PALICC definition, including simplification of radiographic criteria, use of pulse oximetry based metrics to define PARDS, specific criteria for noninvasive ventilation, and the use of oxygenation index (OI) instead of $\mathrm{PaO} 2 / \mathrm{FiO} 2$ ratio for those on invasive ventilation. While these changes could potentially result in major changes in the reported incidence and outcome of PARDS, review of the recent literature since publication of the PALICC definitions highlight that major elements regarding the contemporary epidemiology of PARDS have remained stable over the past 20 years. This highlights that the PARDS definition is likely catching up to changes in clinical practice, and suggests that this new definition should be used moving forward as it is more reflective of current practice than historical definitions. However, it is also clear that PARDS severity alone (as measured by the PALICC) criteria insufficiently characterizes the risk for mortality or other important clinical outcomes amongst PARDS patients, although there appears to be some association between PARDS severity and outcome, particularly when hypoxemia is severe.
\end{abstract}

Keywords: Pediatric acute respiratory distress syndrome (PARDS); acute respiratory distress syndrome (ARDS); Pediatric Acute Lung Injury Consensus Conference (PALICC); definition; epidemiology

Submitted May 31, 2019. Accepted for publication Aug 26, 2019.

doi: $10.21037 /$ atm.2019.09.31

View this article at: http://dx.doi.org/10.21037/atm.2019.09.31

\section{Introduction}

In 1821, Laennec described in his "Treatise on Diseases of the Chest" probably the first published description of acute respiratory distress syndrome (ARDS), however it wasn't until 1967, in a landmark article published in Lancet that the term Acute Respiratory Distress Syndrome "ARDS" was mentioned (1). Ashbaugh and colleagues described a syndrome of tachypnea, hypoxia, and decreased pulmonary compliance in a series of 11 adults and one child with respiratory failure. The pathologic features included interstitial and intra-alveolar edema and hemorrhage, as well as hyaline membrane formation.

Like other clinical syndromes, ARDS lacks a definitive gold standard for diagnosis, so our diagnostic criteria have sought to identify clinical signs and symptoms reflective of the pathobiology of the disease. These relate to the diffuse albeit non homogeneous nature of the injury at both the alveolar epithelial and endothelial surface, inflammation, loss of functional residual capacity and impairment in pulmonary compliance, hypoxemia, and elevations in alveolar dead space. 
Since its description, pediatric intensivists have relied on adult-based definitions of ARDS for patient care, research and prognostication, including both the American European Consensus Conference (AECC) and Berlin Definitions (2-4). Although the pathophysiology of ARDS in adults and children is comparable, practice patterns specific to pediatrics, co-morbidities, and contrasts in outcomes made it clear that a pediatric specific definition was needed (5).

In contrast to the Berlin definition for adult for adult ARDS, the Pediatric Acute Lung Injury Consensus Conference (PALICC) definition (6) simplified radiographic criteria, incorporates pulse oximetry metrics when $\mathrm{PaO}_{2}$ is not available, introduces the use of oxygenation index (OI) and oxygenation saturation index (OSI) to stratify severity groups instead of $\mathrm{PaO}_{2} / \mathrm{FiO}_{2}$ (PF ratio) with minimum positive end-expiratory pressure (PEEP) and creates specific criteria to define ARDS in children with chronic lung disease and cyanotic heart disease. In addition, no upper limit of age is defined for PALICC criteria, although children with perinatal-related lung injuries are excluded. Moreover, PALICC had pediatric specific criteria to define PARDS and at-risk for PARDS in infants and children on non-invasive ventilation. The definitions are summarized in Figures 1 and 2 below. Given the relatively major changes to the definition of ARDS proposed by the PALICC definition, it is important to evaluate the impact the definition will have on the international epidemiology of PARDS.

\section{Incidence of ARDS}

Since 2015, there have been several studies reporting aspects of the epidemiology of ARDS using the PALICC definition (Tables 1,2).Previous studies and meta-analysis using the AECC or Berlin definition estimate the incidence in the US, Europe and Australia and New Zealand to lie between $2-12.8$ per 100,000 person years $(7-12)$, or approximately $1-4 \%$ of PICU patients, or $8-10 \%$ of mechanically ventilated patients. Using Berlin and AECC criteria, Schouten et al. (12) reported the pooled weighted population-based incidence was 3.5 cases per 100,000 person years (95\% CI: 2.2-5.7). The pooled weight PICU based incidence was $2.3 \%$ (95\% CI: 1.9-2.9\%). This trend was stable over time (13-17).

There have been no population-based studies estimating the incidence of PARDS. Interestingly the recently completed Pediatric Respiratory Distress Incidence and Epidemiology (PARDIE) study (18) in 145 international intensive care units, representing 27 countries, found that using the PALICC definition, PARDS occurs in approximately $3 \%$ of PICU patients, or $6 \%$ of those on mechanical ventilation. These results are consistent with previous estimates using AECC and Berlin criteria. So it appears as if the rate of PARDS continues to be stable over time, even when using the PALICC definition. However, PARDIE also found that the PALICC definition identified approximately $40 \%$ more children as having ARDS and diagnosed ARDS a median of 12.8 hours sooner than the Berlin definition within the first 3 days. This is consistent with other, retrospective reports, Gupta et al. (19) and Parvathaneni et al. (20). Reconciling this stable incidence over time with this nearly doubling in number of patients identified with the PALICC criteria highlights that monitoring practices have changed significantly in the last decade, and the requirement for invasive arterial blood gas values to apply Berlin and AECC definitions in current times and moving forward will under-estimate the PARDS incidence/prevalence. For this reason, it is important that future studies regarding the epidemiology of pediatric ARDS use PALICC criteria, including pulse-oximetry.

Notably, there appears to be significant regional and ICU specific variation in the rates of PARDS. From the PARDIE study, among mechanically ventilated patients, the number of new cases of PARDS was highest in North America, high income countries, during non-summer months, and lowest in medium volume PICUs (all $\mathrm{P}<0.01$ ).

\section{ARDS triggers}

Multiple triggers for ARDS have been identified and other potential triggers continue to emerge as adverse pulmonary reactions to new therapies are observed. However, a few common triggers account for most cases of ARDS. In the pediatric population, intrinsic pulmonary processes including Pneumonia or lower respiratory tract infection remains the most common PARDS risk factors. Sepsis remains the second most common risk factor. Several studies have consistently shown this trend (19-26), which is true regardless of which definition is applied. In a secondary analysis of a multicenter retrospective cohort study (23) in Asia, Gan et al. (27) found that pulmonary PARDS accounted for $86.6 \%$ of cases and extrapulmonary PARDS for $13.4 \%$. The most common causes of extrapulmonary PARDS was sepsis $(82.9 \%)$ and for pulmonary PARDS pneumonia (91.7\%). PARDIE (18) confirmed that Pneumonia/lower respiratory tract infection is the leading 
Age: Exclude patients with peri-natal related lung disease

Timing: Within 7 days of known clinical insult

Origin of Edema: Respiratory failure not fully explained by cardiac failure or fluid overload

Chest Imaging: Chest imaging findings of new infiltrate(s) consistent with acute pulmonary parenchymal disease

\begin{tabular}{|c|c|c|}
\hline \multicolumn{3}{|l|}{ Oxygenation } \\
\hline \multicolumn{3}{|c|}{$\begin{array}{l}\text { Non Invasive mechanical ventilation: Full face-mask bi-level } \\
\text { ventilation or CPAP } \geq 5 \mathrm{~cm} \mathrm{H}_{2} \mathrm{O}^{2} \text { with PF ratio } \leq 300 \text { or SF ratio } \leq 264^{1}\end{array}$} \\
\hline \multicolumn{3}{|c|}{ Invasive mechanical ventilation } \\
\hline Mild & Moderate & Severe \\
\hline $\begin{array}{l}4 \leq \mathrm{OI}<8 \\
5 \leq \mathrm{OSI}<7.5^{1}\end{array}$ & $\begin{array}{l}8 \leq \mathrm{OI}<16 \\
7.5 \leq \mathrm{OSI}<12.3^{1}\end{array}$ & $\begin{array}{l}\mathrm{OI} \geq 16 \\
\mathrm{OSI} \geq 12.3^{1}\end{array}$ \\
\hline
\end{tabular}

Cyanotic Heart Disease: standard criteria with an acute deterioration in oxygenation not explained by underlying cardiac disease. Chronic Lung Disease: standard criteria with chest imaging consistent with new infiltrate and acute deterioration in oxygenation from baseline.

Left Ventricular dysfunction: standard criteria with chest imaging changes and acute deterioration in oxygenation not fully explained by left ventricular dysfunction.

$\mathrm{OI}=$ oxygenation index $=\left(\mathrm{FiO}_{2}{ }^{*}\right.$ mean airway pressure $\left.{ }^{*} 100\right) / \mathrm{PaO}_{2}$

$\mathrm{OSI}=$ oxygen saturation index $=\left(\mathrm{FiO}_{2}{ }^{*}\right.$ mean airway pressure $\left.{ }^{*} 100\right) / \mathrm{SpO}_{2}$

${ }^{1}$ Use $\mathrm{PaO}_{2}$ based metric when available. If $\mathrm{PaO}_{2}$ not available, wean $\mathrm{FiO}_{2}$ to maintain $\mathrm{SpO}_{2} \leq 97 \%$ to calculate OSI or SF ratio

${ }^{2}$ For non-intubated patients treated with supplemental oxygen or nasal modes of non invasive ventilation see Figure 2 for At Risk Criteria

Figure 1 PARDS definition. PARDS, pediatric acute respiratory distress syndrome.

Age: Exclude patients with peri-natal related lung disease

Timing: Within 7 days of known clinical insult

Origin of Edema: Respiratory failure not fully explained by cardiac failure or fluid overload

Chest Imaging: Chest imaging findings of new infiltrate(s) consistent with acute pulmonary parenchymal disease

\section{Oxygenation \\ Nasal mask CPAP or BiPAP \\ $\mathrm{FiO}_{2} \geq 40 \%$ to attain $\mathrm{SpO}_{2} 88-97 \%$}

Oxygen via mask, nasal cannula or High Flow

$\mathrm{SpO}_{2}$ 88-97\% with oxygen supplementation at minimum flow ${ }^{2}$ :

$<1$ year: $2 \mathrm{~L} / \mathrm{min}$

1-5 years: $4 \mathrm{~L} / \mathrm{min}$

5-10 years: $6 \mathrm{~L} / \mathrm{min}$

$>10$ years: $8 \mathrm{~L} / \mathrm{min}$

Invasive Mechanical Ventilation

Oxygen supplementation to maintain $\mathrm{SpO}_{2} \geq 88 \%$ but $\mathrm{Ol}<4$ or OSI $<5^{1}$

${ }^{1}$ If $\mathrm{PaO}_{2}$ not available, wean $\mathrm{FiO}_{2}$ to maintain $\mathrm{SpO}_{2} \leq 97 \%$ to calculate OSI

${ }^{2}$ Given lack of available data, for patients on an oxygen blender, flow for at risk calculation $=\mathrm{FiO}_{2}{ }^{*}$ FlowRate $(\mathrm{L} / \mathrm{min})(\mathrm{e} . \mathrm{g}$. $6 \mathrm{~L} / \mathrm{min}$ flow at $0.35 \mathrm{FiO}_{2}=2.1 \mathrm{~L} / \mathrm{min}$ )

Figure 2 At risk of PARDS definition. PARDS, pediatric acute respiratory distress syndrome.

cause of PARDS followed by sepsis. Trauma is reported as a cause of PARDS in $4-8 \%(18,22,25,26,28,29)$, although as recently reported only $1.8 \%$ of critically injured children develop ARDS (by either Berlin or AECC criteria). Motor vehicle crashes are the most common mechanism of injury in pediatric trauma patients who develop ARDS (21).

\section{Co-morbidities}

Pre-existing co-morbidities are common amongst PARDS patients (12-74\%). The PARDIE study showed that $63 \%$ of patients with PARDS have co-morbidities. Preexisting lung disease was the most prevalent (28\%), followed by prematurity (19\%), chronic respiratory support $(17 \%)$ and a history of congenital heart disease (11\%). Interestingly because the PALICC definition (like the Berlin definition) allowed cardiac disease and ARDS to co-exist, PARDIE found that $8 \%$ of PARDS patients had acquired heart disease and $6 \%$ had documented left ventricular dysfunction. Immune suppression and cancer 
Table 1 Studies reporting the epidemiology of ARDS

\begin{tabular}{|c|c|c|c|c|}
\hline Region/type & Study design & Study & Authors & Year \\
\hline \multirow{2}{*}{$\begin{array}{l}\text { Children's Hospital } \\
\text { Philadelphia (CHOP), } \\
\text { USA }\end{array}$} & & $\begin{array}{l}\text { New morbidity and discharge disposition of } \\
\text { pediatric acute respiratory distress syndrome } \\
\text { survivors }\end{array}$ & $\begin{array}{l}\text { Keim G, Watson RS, Thomas NJ, } \\
\text { Yehya N }\end{array}$ & 2018 \\
\hline & & $\begin{array}{l}\text { Characterizing degree of lung injury in pediatric } \\
\text { acute respiratory distress syndrome. Critical } \\
\text { care medicine }\end{array}$ & Yehya N, Servaes S, Thomas NJ & 2015 \\
\hline $\begin{array}{l}\text { Multi-center CHLA/ } \\
\text { CHOP, USA }\end{array}$ & $\begin{array}{l}\text { Prospective/ } \\
\text { retrospective }\end{array}$ & $\begin{array}{l}\text { Epidemiology of cause of death in pediatric } \\
\text { acute respiratory distress syndrome }\end{array}$ & $\begin{array}{l}\text { Dowell JC, Parvathaneni K, Thomas NJ, } \\
\text { Khemani RG, Yehya N }\end{array}$ & 2018 \\
\hline $\begin{array}{l}\text { Single Center, All } \\
\text { India Institute of } \\
\text { Medical Sciences, } \\
\text { India }\end{array}$ & $\begin{array}{l}\text { Retrospective } \\
\text { cohort }\end{array}$ & $\begin{array}{l}\text { Comparison of prevalence and outcomes of } \\
\text { pediatric acute respiratory distress syndrome } \\
\text { using pediatric acute lung injury consensus } \\
\text { conference criteria and berlin definition }\end{array}$ & Gupta S, Sankar J, Lodha R, Kabra SK & 2018 \\
\hline $\begin{array}{l}\text { Multicenter, } 12 \text { ICUs } \\
\text { in the United States }\end{array}$ & $\begin{array}{l}\text { Retrospective } \\
\text { cohort }\end{array}$ & $\begin{array}{l}\text { Pediatric acute respiratory distress syndrome } \\
\text { in pediatric allogeneic hematopoietic stem cell } \\
\text { transplants: a multicenter study }\end{array}$ & $\begin{array}{l}\text { Rowan CM, Smith LS, Loomis A, } \\
\text { et al. Investigators of the Pediatric Acute } \\
\text { Lung Injury and Sepsis Network }\end{array}$ & 2017 \\
\hline
\end{tabular}

ARDS, acute respiratory distress syndrome.

was also very common and represented $21 \%$ of all patients. Immune suppression was an independent risk factor for mortality, which is consistent with multiple previous studies $(8,9,16,17,29-34)$.

\section{Outcomes}

Two meta-analyses conducted using Berlin and AECC definitions have highlighted that there appears to be a reduction in overall mortality amongst children with ARDS over time, with cumulative estimates converging around $20-30 \%$ in recent years $(12,24)$. Many studies which have used the PALICC definition in the last several years have identified similar mortality rates $(20,24,27)$ although mortality has been reported as being $<20 \%$ in some cohort studies, including the PARDIE study $(18,22)$. Importantly, there appears to be significant regional heterogeneity in mortality, which may be related to income disparities, health care systems, or a variety of other factors $(12,18,19,24)$.

Hypoxemia severity has been suggested to stratify risk 
Table 2 Studies reporting the mortality of ARDS

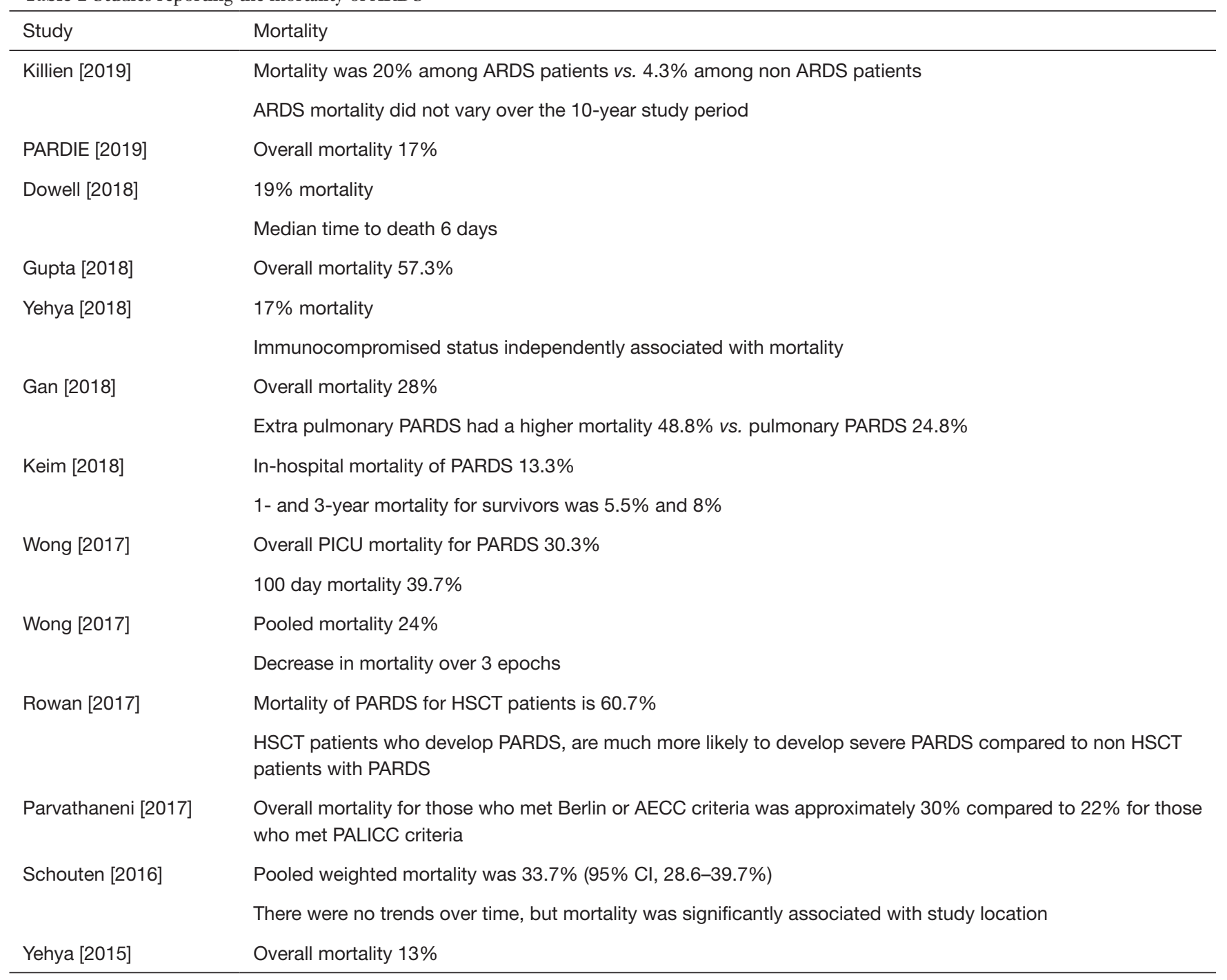

ARDS, acute respiratory distress syndrome; PARDS, pediatric acute respiratory distress syndrome.

in current ARDS definitions (both Berlin and PALICC). Some studies have been able to identify a relationship between initial PALICC (or Berlin) severity and important clinical outcomes such as ventilator free days or mortality $(18,23,24,27)$. However, others have been unable to reproduce this relationship at PARDS onset (22), or highlight that severe disease at PARDS onset discriminates mortality, with little difference between those with NIV, mild, or moderate disease $(18,20)$, including those who have undergone a stem cell-transplant (35). Interestingly, a delayed measure of hypoxemia appears to improve mortality risk stratification $(18,20,22)$. Previous studies have suggested waiting 12-24 hours after PARDS diagnosis to stratify risk, but the PARDIE study suggests this can be done approximately 6 hours after PARDS diagnosis.

In addition to hypoxemia severity, it is clear that the ARDS trigger is associated outcome. Using AECC and Berlin definitions of ARDS, Schouten et al. (12) found in their meta-analysis that patients with indirect lung injury (e.g., sepsis) had a significantly higher mortality than patients with direct lung injury (e.g., pneumonia), OR 3.29 (2.22-4.86, $\mathrm{P}<0.001)$. These findings appears to hold even when applying PALICC definitions, with several studies suggesting higher initial severity of illness for those with extra-pulmonary PARDS, more organ failure, higher mortality, and fewer ventilator free days $(25,27)$. In addition, 
patients with indirect lung injury were more likely to be immune compromised (25). In the PARDIE study, immune compromised state and non-pulmonary ARDS retained a significant association with mortality, even after controlling for hypoxemia severity (18).

There are few published articles describing the cause of death in pediatric ARDS. Adult studies have shown that refractory hypoxemia is an uncommon cause of death in ARDS, and the leading cause of death is multisystem organ failure (MSOF) or neurologic factors $(36,37)$. The same holds with pediatric ARDS. It is still not clear whether the mortality is primarily due to PARDS, aggravated by PARDS or associated with the inciting insult or comorbidities. Dowell et al. (26) performed a retrospective observational study of all nonsurvivors of PARDS at the Children's Hospital of Philadelphia (CHOP) and the Children's Hospital of Los Angeles (CHLA). They report an overall mortality of $19 \%$, and after PARDS onset a median time to death of 6 days (IQR, 3-13 days). Greater PARDS severity and higher PRISM scores were associated with earlier deaths. Immunocompromised patients accounted for $35 \%$ of all non survivors and comprised $51 \%$ of late ( $>7$ days) deaths. Patients who died within 7 days after PARDS onset were more prone to die of a neurologic cause of death. MSOF was the leading cause of death for patients who died greater than or equal to 7 days after PARDS onset. And $20 \%$ of PARDS patients died from refractory hypoxemia and this was also more common in those who died greater than or equal to 7 days after PARDS onset. Similarly in the PARDIE study, $34 \%$ of deaths were thought to be primarily related to refractory hypoxemia, $43 \%$ to multiple organ failure, $28 \%$ to neurologic injury, and $18 \%$ to unresolving shock.

In addition to high rates of mortality and long lengths of ventilation, it is increasingly recognized that many PARDS survivors have new morbidity after ICU discharge. Keim et al. (28) found that, $23 \%$ of PARDS survivors had new morbidity after ICU discharge, most notably a decline in functional status. Watson and colleagues have recently corroborated these findings in a large cohort study of mechanically ventilated children identifying approximately $20 \%$ have impaired health-related quality of life and functional status, and this is associated with etiology of respiratory failure and duration of mechanical ventilation $(38,39)$. In addition post-ICU morbidity is very common in pediatric trauma patients who develop ARDS, with a nearly 4-fold higher risk of being discharged to a rehabilitation facility compared to trauma patients who do not develop
ARDS (21).

\section{Conclusions}

In conclusion, the PALICC criteria have created a contemporary standard to define pediatric ARDS which is reflective of current practice patterns. A series of recent investigations have demonstrated these criteria, when applied to recent cohorts, identify many more patients with ARDS in current practice, compared to AECC or Berlin definitions. Nevertheless, there are consistent percentages of patients identified as having ARDS between current cohorts with the PALICC definition, and historical cohorts using the AECC or Berlin Definition. This highlights that the overall rate of ARDS is likely not changing over time, but that the PALICC definition is necessary in current times to ensure we are identifying all patients with ARDS. It is likely that many patients who meet PALICC criteria now would have been identified with Berlin or AECC 20 or 30 years ago, but are not currently identified by Berlin or AECC given changes in clinical practice with regards to respiratory monitoring. This reinforces the importance of using PALICC criteria moving forward for future epidemiologic studies of PARDS. However, it is also clear that PARDS severity alone (as measured by the PALICC) criteria insufficiently characterizes the risk for mortality or other important clinical outcomes amongst PARDS patients, although there appears to be some association between PARDS severity and outcome, particularly when hypoxemia is severe.

\section{Acknowledgments}

None.

\section{Footnote}

Conflicts of Interest: The authors have no conflicts of interest to declare.

Ethical Statement: The authors are accountable for all aspects of the work in ensuring that questions related to the accuracy or integrity of any part of the work are appropriately investigated and resolved.

\section{References}

1. Ashbaugh DG, Bigelow DB, Petty TL, et al. Acute 
respiratory distress in adults. Lancet 1967;2:319-23.

2. Bernard GR, Artigas A, Brigham KL, et al. The American-European Consensus Conference on ARDS. Definitions, mechanisms, relevant outcomes, and clinical trial coordination. Am J Respir Crit Care Med 1994;149:818-24.

3. Ferguson ND, Fan E, Camporota L, et al. The Berlin definition of ARDS: an expanded rationale, justification, and supplementary material. Intensive Care Med 2012;38:1573-82.

4. ARDS Definition Task Force, Ranieri VM, Rubenfeld GD, et al. Acute respiratory distress syndrome: the Berlin Definition. JAMA 2012;307:2526-33.

5. Thomas NJ, Jouvet P, Willson D. Acute lung injury in children--kids really aren't just "little adults". Pediatr Crit Care Med 2013;14:429-32.

6. Pediatric Acute Lung Injury Consensus Conference Group. Pediatric acute respiratory distress syndrome: consensus recommendations from the Pediatric Acute Lung Injury Consensus Conference. Pediatr Crit Care Med 2015;16:428-39.

7. Gajic O, Dabbagh O, Park PK, et al. Early identification of patients at risk of acute lung injury: evaluation of lung injury prediction score in a multicenter cohort study. Am J Respir Crit Care Med 2011;183:462-70.

8. Erickson S, Schibler A, Numa A, et al. AaNZIC: Acute lung injury in pediatric intensive care in Australia and New Zealand: a prospective, multicenter, observational study. Pediatr Crit Care Med 2007;8:317-23.

9. López-Fernández Y, Azagra AM-d, de la Oliva P, et al. Pediatric Acute Lung Injury Epidemiology and Natural History Study: Incidence and outcome of the acute respiratory distress syndrome in children. Crit Care Med 2012;40:3238-45.

10. Kneyber MCJ, Brouwers AGA, Caris JA, et al. Acute respiratory distress syndrome: is it underrecognized in the pediatric intensive care unit? Intensive Care Med 2008;34:751-4.

11. Bindl L, Dresbach K, Lentze MJ. Incidence of acute respiratory distress syndrome in German children and adolescents: a population-based study. Crit Care Med 2005;33:209-312.

12. Schouten LR, Veltkamp F, Bos AP, et al. Incidence and Mortality of Acute Respiratory Distress Syndrome in Children: A Systematic Review and Meta-Analysis. Crit Care Med 2016;44:819-29.

13. Rubenfeld GD, Caldwell E, Peabody E, et al. Incidence and outcomes of acute lung injury. N Engl J Med
2005;353:1685-93.

14. Bersten AD, Edibam C, Hunt T, et al. New Zealand Intensive Care Society Clinical Trials. Incidence and mortality of acute lung injury and the acute respiratory distress syndrome in three Australian States. Am J Respir Crit Care Med 2002;165:443-8.

15. Li G, Malinchoc M, Cartin-Ceba R, et al. Eight-year trend of acute respiratory distress syndrome: a populationbased study in Olmsted County, Minnesota. Am J Respir Crit Care Med 2011;183:59-66.

16. Luhr OR, Antonsen K, Karlsson M, et al. Incidence and mortality after acute respiratory failure and acute respiratory distress syndrome in Sweden, Denmark, and Iceland. The ARF Study Group. Am J Respir Crit Care Med 1999;159:1849-61.

17. Brun-Buisson C, Minelli C, Bertolini G, et al. Epidemiology and outcome of acute lung injury in European intensive care units. Results from the ALIVE study. Intensive Care Med 2004;30:51-61.

18. Khemani RG, Smith L, Lopez-Fernandez YM, et al. Paediatric acute respiratory distress syndrome incidence and epidemiology (PARDIE): an international, observational study. Pediatric Acute Respiratory Distress syndrome Incidence and Epidemiology (PARDIE) Investigators; Pediatric Acute Lung Injury and Sepsis Investigators (PALISI) Network. Lancet Respir Med 2019;7:115-28.

19. Gupta S, Sankar J, Lodha R, et al. Comparison of Prevalence and Outcomes of Pediatric Acute Respiratory Distress Syndrome using Using Pediatric Acute Lung Injury Consensus Conference Criteria and Berlin Definition. Front Pediatr 2018;6:93.

20. Parvathaneni K, Belani S, Leung D, et al. Evaluating the Performance of the Pediatric Acute Lung Injury Consensus Conference Definition of Acute Respiratory Distress Syndrome. Pediatr Crit Care Med 2017;18:17-25.

21. Killien EY, Mills B, Watson RS, et al. Morbidity and Mortality Among Critically Injured Children With Acute Respiratory Distress Syndrome. Crit Care Med 2019;47:e112-9.

22. Yehya N, Servaes S, Thomas NJ. Characterizing degree of lung injury in pediatric acute respiratory distress syndrome. Crit Care Med 2015;43:937-46.

23. Wong JJ, Phan HP, Phumeetham S, et al. Risk Stratification in Pediatric Acute Respiratory Distress Syndrome: A Multicenter Observational Study. Crit Care Med 2017;45:1820-8.

24. Wong JJ, Jit M, Sultana R, et al. Mortality in Pediatric 
Acute Respiratory Distress Syndrome: A Systematic Review and Meta-Analysis. J Intensive Care Med 2019;34:563-71.

25. Yehya N, Keim G, Thomas NJ. Subtypes of pediatric acute respiratory distress syndrome have different predictors of mortality. Intensive Care Med 2018;44:1230-9.

26. Dowell JC, Parvathaneni K, Thomas NJ, et al. Epidemiology of Cause of Death in Pediatric Acute Respiratory Distress Syndrome. Crit Care Med 2018;46:1811-9.

27. Gan CS, Wong JJ, Samransamruajkit R, et al. Pediatric Acute and Critical Care Medicine Asian Network (PACCMAN). Differences Between Pulmonary and Extrapulmonary Pediatric Acute Respiratory Distress Syndrome: A Multicenter Analysis. Pediatr Crit Care Med 2018;19:e504-13.

28. Keim G, Watson RS, Thomas NJ, et al. New Morbidity and Discharge Disposition of Pediatric Acute Respiratory Distress Syndrome Survivors. Crit Care Med 2018;46:1731-8.

29. Johnston CJ, Rubenfeld GD, Hudson LD. Effect of age on the development of ARDS in trauma patients. Chest 2003;124:653-9.

30. Zimmerman JJ, Akhtar SR, Caldwell E, et al. Incidence and outcomes of pediatric acute lung injury. Pediatrics 2009;124:87-95.

31. Yu WL, Lu ZJ, Wang Y, et al. The epidemiology of acute respiratory distress syndrome in pediatric intensive care units in China. Intensive Care Med 2009;35:136-43.

32. Santschi M, Jouvet P, Leclerc F, et al. Acute lung injury in children: therapeutic practice and feasibility of international clinical trials. Pediatr Crit Care Med 2010;11:681-9.

Cite this article as: Beltramo F, Khemani RG. Definition and global epidemiology of pediatric acute respiratory distress syndrome. Ann Transl Med 2019;7(19):502. doi: 10.21037/ atm.2019.09.31
33. Hu X, Qian S, Xu F, et al. Incidence, management and mortality of acute hypoxemic respiratory failure and acute respiratory distress syndrome from a prospective study of Chinese paediatric intensive care network. Acta Paediatr 2010;99:715-21.

34. Bindl L, Buderus S, Dahlem P, et al. Gender-based differences in children with sepsis and ARDS: the ESPNIC ARDS Database Group. Intensive Care Med 2003;29:1770-3.

35. Rowan CM, Smith LS, Loomis A, et al. Pediatric Acute Respiratory Distress Syndrome in Pediatric Allogeneic Hematopoietic Stem Cell Transplants: A Multicenter Study. Pediatr Crit Care Med 2017;18:304-9.

36. Stapleton RD, Wang BM, Hudson LD, et al. Causes and timing of death in patients with ARDS. Chest 2005;128:525-32.

37. Villar J, Martínez D, Mosteiro F, et al. Stratification and Outcome of Acute Respiratory Distress Syndrome (STANDARDS) Network. Is Overall Mortality the Right Composite Endpoint in Clinical Trials of Acute Respiratory Distress Syndrome? Crit Care Med 2018;46:892-9.

38. Watson RS, Asaro LA, Hutchins L, et al. RESTORE Study Investigators. Risk Factors for Functional Decline and Impaired Quality of Life after Pediatric Respiratory Failure. Am J Respir Crit Care Med 2019. [Epub ahead of print].

39. Watson RS, Asaro LA, Hertzog JH, et al. RESTORE Study Investigators and the Pediatric Acute Lung Injury and Sepsis Investigators (PALISI) Network. Long-Term Outcomes after Protocolized Sedation versus Usual Care in Ventilated Pediatric Patients. Am J Respir Crit Care Med 2018;197:1457-67. 